\title{
Equações para a estimativa do índice de área foliar do cafeeiro(1)
}

\author{
José Laércio Favarin(2), Durval Dourado Neto(3) $^{(3)}$ Axel García y García(2), \\ Nilson Augusto Villa Nova ${ }^{(4)}$ e Maria da Graça Guilherme Vieira Favarin(2)
}

\begin{abstract}
Resumo - Com o objetivo de estudar a variação temporal do índice de área foliar (IAF) da cultura de café, utilizando um método simples e não-destrutivo, foi instalado um experimento no Departamento de Produção Vegetal, da Escola Superior de Agricultura Luiz de Queiroz, da Universidade de São Paulo. Utilizou-se a cultivar Mundo Novo IAC 388-17, enxertada sobre a cultivar Apoatã IAC 2258 (de 15 até 35 meses de idade), no espaçamento de 2,5 x 1,0 m. Foram coletadas todas as folhas de duas plantas de café, em intervalos de 60 a 150 dias, para a mensuração da área foliar com o equipamento LI-COR (modelo 3100). Para obter a relação funcional entre IAF e diferentes variáveis de crescimento (altura da planta, número e massa total de folhas e área foliar) e arquitetura da copa (área da seção inferior, média e superior do dossel, área lateral do dossel, diâmetro inferior, médio e superior do dossel, volume do dossel da planta e altura do primeiro par de ramos), assumiu-se que a parte aérea do cafeeiro tem a forma cônica. O diâmetro da seção inferior do dossel (primeiro par de ramos) e a altura da planta podem ser utilizadas para estimar o índice de área foliar do cafeeiro.
\end{abstract}

Termos para indexação: Coffea arabica, dossel, culturas perenes, modelos.

\section{Equations for estimating the coffee leaf area index}

\begin{abstract}
With the purpose of estimating the temporal variation of the coffee leaf area index (LAI), using a non destructive simple methodology, an experiment was carried out at the Crop Production Department, Escola Superior de Agricultura Luiz de Queiroz, of the Universidade de São Paulo, Piracicaba, SP, Brazil. The Mundo Novo IAC 388-17 cultivar, grafted on the cultivar Apoatã IAC 2258 (15 to 35 months old), was used with a distance between plants of $2.5 \mathrm{~m} \times 1.0 \mathrm{~m}$, where all leaves of two coffee plants were collected, with intervals varying from 60 to 150 days, to measure the leaf area using the LI-COR equipment (model 3100). To obtain the functional relationship between the LAI and different growth variables (plant height, total number and mass of leaves and leaf area) and the canopy architecture (inferior, medium and superior crop canopy area; crop canopy lateral area; inferior, medium and superior canopy diameter; the plant canopy volume; and the first two branches height), a conic shape for aerial plant architecture was assumed. The inferior canopy diameter (first two branches) and the plant height can be used to estimate the coffee leaf area index.
\end{abstract}

Index terms: Coffea arabica, canopy, perennial crops, models.

(1) Aceito para publicação em 10 de setembro de 2001 . Extraído da pesquisa referente ao estágio de experimentação apresentado pelo primeiro autor à Escola Superior de Agricultura Luiz de Queiroz (Esalq), Piracicaba, SP.

(2) Esalq, Dep. de Produção Vegetal, Caixa Postal 9, CEP 13418-970 Piracicaba, SP. E-mail: jlfavari@carpa.ciagri.usp.br, aggarcia@carpa.usp.br

(3) Esalq, Dep. de Produção Vegetal. Bolsista do CNPq. E-mail: dourado@carpa.ciagri.usp.br

(4) Esalq, Dep. de Ciências Exatas. Bolsista do CNPq. E-mail: lrangelo@carpa.ciagri.usp.br

\section{Introdução}

O índice de área foliar (IAF, $\mathrm{m}^{2} \mathrm{~m}^{-2}$ ) é a relação funcional existente entre a área foliar e a área do terreno ocupada pela cultura. Considerando que o rendimento agrícola é expresso pela quantidade de matéria colhida por unidade de área, é válido expressar a área foliar sobre a mesma base do rendimento (Watson, 1952). 
A importância da área foliar de uma cultura é amplamente conhecida por ser um parâmetro indicativo de produtividade, pois o processo fotossintético depende da interceptação da energia luminosa e a sua conversão em energia química. De acordo com Leong (1980), a eficiência fotossintética depende da taxa fotossintética por unidade de área foliar e da interceptação da radiação solar, as quais, entre outros aspectos, são influenciadas pelas características da arquitetura da copa e da dimensão do sistema fotoassimilador.

Assim sendo, a superfície foliar de uma planta é a base do rendimento potencial da cultura. Além disso, o conhecimento da área foliar da planta permite a estimativa da perda de água, uma vez que as folhas são os principais órgãos que participam no processo transpiratório, responsável pela troca gasosa com o ambiente (Pereira et al., 1997). Do exposto, o conhecimento da variação temporal do índice de área foliar em culturas perenes poderá ser útil na avaliação de várias práticas culturais como poda, adubação, irrigação, espaçamento e aplicação de defensivos, entre outros.

Inúmeros trabalhos foram realizados para determinar a variação temporal do índice de área foliar de culturas anuais como milho, arroz e feijão, porém, essa variação é pouco estudada em culturas perenes. No Brasil, praticamente não há trabalhos de pesquisa sobre essa variável na cultura de café, e são escassas as referências bibliográficas sobre o assunto.

Atualmente, é crescente a adoção da técnica de irrigação de cafezais em diferentes regiões do país (Santinato et al., 1997). A utilização racional da referida técnica depende do conhecimento da variação temporal do índice de área foliar (IAF), considerando que a área foliar da cultura é responsável pelas maiores perdas de água. Assim, o estudo dessa variável permitirá estimar as variações nas necessidades hídricas da cultura, bem como definir as melhores estratégias de manejo da irrigação, proporcionando maior eficiência econômica e também ambiental, devido à escassez deste recurso para fins agrícolas.

Segundo Valencia (1973), o uso do IAF na planta de café foi sugerido por Castillo, na Colombia, em 1961, sendo que Huerta \& Alvim (1962) foram os primeiros pesquisadores que desenvolveram trabalhos sobre o assunto. Valencia (1973) desenvolveu um trabalho relacionando o IAF com o máximo rendimento do cafeeiro, em razão da densidade de plantio. De acordo com os resultados, o rendimento máximo da cultura foi obtido quando o IAF da cultura atingiu o valor igual a oito, que ocorreu três anos após o plantio para uma população de 10.000 plantas ha-1, e, somente depois do $4^{\circ}$ ano após o plantio, quando a população era de 5.000 plantas ha-1.

Rey \& Alvarez (1991), trabalhando em condições de viveiro, avaliaram modelos de estimativa da área foliar da planta de café. Os referidos pesquisadores relacionaram o comprimento e a largura das folhas da planta com a área foliar, adotando diferentes modelos: linear, quadrático, radical e potencial. O resultado deste trabalho recomenda a utilização do modelo linear. A principal limitação desta proposta é o tempo necessário para realizar a determinação do comprimento e da largura de cada folha pois, dependendo da idade da planta, pode-se encontrar uma quantidade superior a 4.000 folhas por planta.

O presente trabalho teve como objetivo obter a relação funcional entre o IAF da cultura de café e as diferentes variáveis de crescimento e de arquitetura da parte aérea.

\section{Material e Métodos}

O experimento foi realizado no campo experimental do Departamento de Produção Vegetal da Esalq/USP em uma lavoura de café da cultivar Mundo Novo IAC 388-17, enxertada na cultivar Apoatã IAC 2258 plantada com espaçamento de $2,5 \times 1,0 \mathrm{~m}$. As avaliações foram iniciadas a partir do $15^{\circ}$ mês após o plantio das mudas no campo e continuou até o $35^{\circ}$ mês, utilizando-se um método destrutivo para o acompanhamento da variação temporal do índice de área foliar. Para cada época foram coletadas todas as folhas de duas plantas, em intervalos variáveis de 60 a 150 dias, empregando-se um integrador de área foliar de marca LI-COR (modelo 3100).

Tendo admitido a forma cônica para o dossel do cafeeiro, a partir do primeiro par de ramos plagiotrópicos, foram avaliadas as variações temporais da arquitetura da parte aérea como a área da seção inferior, média e superior do dossel, área lateral e volume do dossel, diâmetro inferior, médio e superior do dossel, e altura de inserção do primeiro par de ramos (Assmann, 1970). Paralelamente, foram observadas as diferentes variáveis de crescimento, altura da planta, número e massa total de folhas e a área foliar. 
As determinações das variáveis de crescimento (altura da planta - ht), e da arquitetura de parte aérea (diâmetro inferior - Di, diâmetro médio - Dm, diâmetro superior do dossel - Ds, e a altura de inserção do primeiro par de ramos - hi), bem como a altura do dossel da planta (Hd), foram obtidas conforme esquematizado na Figura 1.

A partir dos dados coletados, determinou-se a variação temporal da área lateral e do volume do dossel, representado pela figura geométrica cônica, e também as áreas das seções média e superior do dossel da planta de café. Além disso, determinou-se a variação temporal da massa de matéria seca de folhas após secagem em estufa a $70^{\circ} \mathrm{C}$ durante 36 horas, até a obtenção de massa constante. O IAF foi calculado por meio da relação funcional entre a área foliar (AF) e a área disponível às plantas, dada pelo espaçamento (2,5 x 1,0 m), e, posteriormente, relacionou-se o IAF, através de regressão linear simples, com as variáveis observadas.

Para a determinação da área lateral do dossel foi utilizada a equação 1 :

$\mathrm{Ac}=\pi \mathrm{Di}\left(\mathrm{Di}^{2}+4 \mathrm{Hd}^{2}\right)^{0,5} / 4$,

em que Ac corresponde à área do dossel $\left(\mathrm{m}^{2}\right)$; Di, ao diâmetro da seção inferior do dossel $(\mathrm{m})$; e Hd, à altura do dossel da planta $(\mathrm{m})$ obtido pela diferença entre a altura da planta (ht) e a altura de inserção do primeiro par de ramos plagiotrópicos (hi), conforme Figura 1.

O cálculo do volume do dossel foi realizado empregando-se a equação 2 :

$\mathrm{Vc}=\pi \mathrm{Di}{ }^{2} \mathrm{Hd} / 12$,

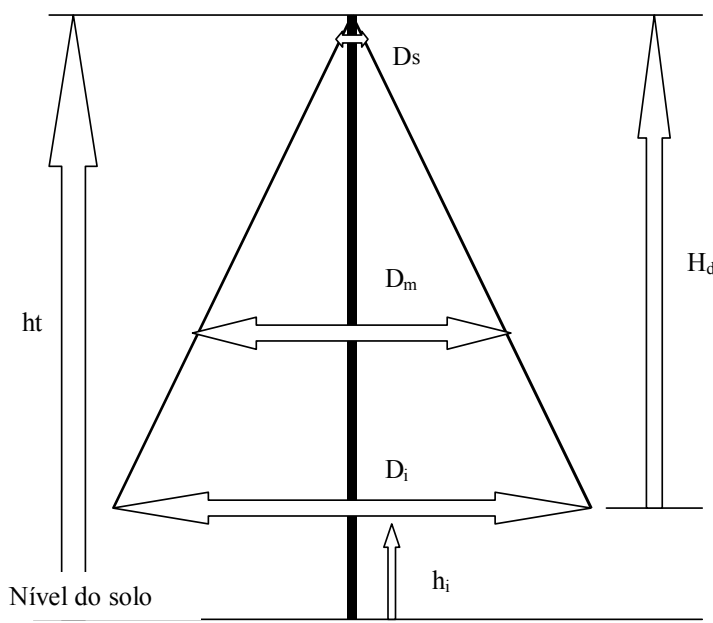

Figura 1. Variáveis de arquitetura de parte aérea da planta de café: ht: altura (m) da planta, Hd: altura (m) do dossel, hi: altura (m) de inserção do primeiro par de ramos plagiotrópicos, Di: diâmetro (m) da seção inferior do dossel, Dm: diâmetro (m) da seção média do dossel, e Ds: diâmetro (m) da seção superior do dossel. em que Vc corresponde ao volume do dossel $\left(\mathrm{m}^{3}\right)$; Di, ao diâmetro da seção inferior do dossel (m); e Hd, à altura do dossel da planta $(\mathrm{m})$ obtido pela diferença entre a altura da planta (ht) e a altura de inserção do primeiro par de ramos plagiotrópicos (hi) (Figura 1).

O IAF $\left(\mathrm{m}^{2} \mathrm{~m}^{-2}\right)$ foi estimado pela substituição dos valores determinados para cada variável independente de acordo com a equação 3 :

IAF $=\alpha+\beta$ X,

em que $\alpha$ e $\beta$ se referem aos parâmetros empíricos do modelo linear determinados por análise de regressão pelo método dos quadrados mínimos, e $\mathrm{X}$, à variável independente, utilizada com o objetivo de verificar qual parâmetro (massa de matéria seca das folhas, número total de folhas por planta, altura das plantas, volume do dossel, área lateral do dossel, área da seção inferior do dossel, diâmetro da seção inferior do dossel, área da seção média do dossel, diâmetro da seção média do dossel, altura do primeiro par de ramos, diâmetro da seção superior do dossel e área da seção superior do dossel) melhor se relaciona com índice de área foliar.

\section{Resultados e Discussão}

Com exceção da altura do primeiro ramo plagiotrópico, do diâmetro da seção superior do dossel e, conseqüentemente, da sua área, as demais variáveis apresentaram valores crescentes (Tabela 1). A variação de altura da inserção da primeira ramificação plagiotrópica deve-se às irregularidades do solo e à diferença de profundidade de plantio das mudas, ao passo que a variação de diâmetro da seção superior do dossel é influenciada pelo momento da avaliação em relação à emissão do último par de ramos plagiotrópicos. Quando a avaliação é realizada tardiamente, o diâmetro da seção será maior, comparativamente à determinação realizada logo após a sua emissão. O decréscimo da altura da planta entre $22 \mathrm{e}$ 25 meses após o plantio se dá por causa da amostragem aleatória das plantas no campo, e, porque representa o valor médio desta variável (médias de duas plantas por época) realizada em plantas com desenvolvimento semelhante às amostradas na época anterior (22 meses). Os mesmos argumentos explicam a diminuição do diâmetro da seção inferior do dossel entre 25 e 28 meses, e do diâmetro da seção média do dossel entre 28 e 30 meses.

Quanto à ordem de grandeza, o IAF observado em plantas com 35 meses após o plantio é semelhan- 
te ao encontrado por Valencia (1973) em densidades de plantas variando entre 2.500 e 10.000 plantas ha $^{-1}$.

As variáveis de arquitetura de parte aérea de planta, como a altura do primeiro par de ramos plagiotrópicos (modelo 10), diâmetro da seção superior do dossel (modelo 11) e área da seção superior do dossel (modelo 12), não apresentaram diferença significativa (Tabela 2). Por outro lado, a variável de crescimento - como a altura da planta (modelo 3 ) - e as variáveis de arquitetura de copa - como o diâmetro da seção inferior do dossel (modelo 7), a área da seção média do dossel (modelo 8) e o diâmetro da seção média do dossel (modelo 9) - ajustaram-se razoavelmente quando correlacionadas (modelo linear) com o índice de área foliar, conforme indicam os respectivos coeficientes de correlação.

As variáveis de crescimento, a massa de matéria seca das folhas (modelo 1) e o número total de folhas

Tabela 1. Médias dos resultados obtidos de duas plantas em relação aos parâmetros determinados, índice da área foliar (IAF), altura da planta (ht), altura de inserção do primeiro par de ramos plagiotrópicos (hi), altura do dossel (Hd), diâmetro da seção inferior (Di), média (Dm) e superior do dossel (Ds), área foliar (AF), área lateral do dossel (Ac), área da seção inferior (Ai), média (Am) e superior (As) do dossel, volume do dossel (Vc), e número (N) e massa de matéria seca de folhas (MMSF).

\begin{tabular}{ccccccccccccccccc}
\hline Idade $^{(1)}$ & $\begin{array}{c}\text { IAF } \\
\left(\mathrm{m}^{2} \mathrm{~m}^{-2}\right)\end{array}$ & ht & hi & Hd & Di & Dm & Ds & AF & Ac & $\begin{array}{c}\text { Ai } \\
\text { Am }\end{array}$ & As & $\begin{array}{c}\text { Vc } \\
\left(\mathrm{m}^{3}\right)\end{array}$ & $\begin{array}{c}\text { N } \\
\text { MMSF } \\
(\mathrm{kg})\end{array}$ \\
\hline 15 & 0,27 & 0,77 & 0,27 & 0,50 & 0,78 & 0,35 & 0,07 & 0,67 & 0,78 & 0,47 & 0,09 & 0,0038 & 0,08 & 321 & 0,07 \\
17 & 0,58 & 1,00 & 0,31 & 0,69 & 1,06 & 0,51 & 0,05 & 1,45 & 1,45 & 0,88 & 0,21 & 0,0026 & 0,20 & 518 & 0,15 \\
20 & 0,68 & 1,05 & 0,34 & 0,71 & 1,18 & 0,55 & 0,16 & 1,69 & 1,71 & 1,09 & 0,24 & 0,0198 & 0,26 & 814 & 0,17 \\
22 & 1,07 & 1,17 & 0,36 & 0,81 & 1,40 & 0,94 & 0,15 & 2,70 & 2,35 & 1,55 & 0,70 & 0,0189 & 0,42 & 1.187 & 0,24 \\
25 & 1,82 & 1,13 & 0,38 & 0,75 & 1,70 & 1,02 & 0,12 & 4,54 & 3,03 & 2,29 & 0,81 & 0,0106 & 0,57 & 1.798 & 0,41 \\
28 & 1,85 & 1,48 & 0,36 & 1,12 & 1,49 & 1,08 & 0,06 & 4,61 & 3,15 & 1,79 & 0,92 & 0,0029 & 0,67 & 2.653 & 0,45 \\
30 & 2,34 & 1,54 & 0,32 & 1,22 & 1,67 & 0,87 & 0,07 & 5,86 & 3,88 & 2,20 & 0,59 & 0,0041 & 0,89 & 3.637 & 0,57 \\
35 & 3,41 & 1,61 & 0,32 & 1,29 & 1,89 & 1,16 & 0,16 & 8,53 & 4,75 & 2,81 & 1,06 & 0,0201 & 1,21 & 3.642 & 0,66 \\
\hline
\end{tabular}

(1)Meses após o plantio do cafeeiro no campo.

Tabela 2. Resumo estatístico dos parâmetros do modelo linear para as variáveis de crescimento (massa de matéria seca de folhas, número de folhas por planta e altura da planta) e para as variáveis de arquitetura (volume do dossel, área lateral do dossel, área da seção inferior do dossel, diâmetro da seção inferior do dossel, área da seção média do dossel, diâmetro da seção média do dossel, altura do primeiro par de ramos, diâmetro da seção superior do dossel e área da seção superior do dossel).

\begin{tabular}{|c|c|c|c|c|c|c|}
\hline \multirow[t]{2}{*}{ Modelo } & \multirow[t]{2}{*}{ Variável (X) } & \multirow[t]{2}{*}{ Unidade } & \multicolumn{2}{|c|}{$\mathrm{IAF}=\alpha+\beta \mathrm{X}$} & \multirow[t]{2}{*}{$\mathrm{r}^{2}$} & \multirow[t]{2}{*}{$\mathrm{F}$} \\
\hline & & & $\alpha$ & $\beta$ & & \\
\hline 1 & Massa de matéria seca de folhas & $\mathrm{kg}$ & $-0,1484$ & 4,8599 & 0,9690 & $* *$ \\
\hline 2 & Número de folhas por planta & - & $+0,1455$ & 0,0007 & 0,9003 & $* *$ \\
\hline 3 & Altura da planta & $\mathrm{m}$ & $-2,4706$ & 3,2603 & 0,8328 & $* *$ \\
\hline 4 & Volume do dossel (equação 2) & $\mathrm{m}^{3}$ & $+0,0134$ & 2,7791 & 0,9893 & $* *$ \\
\hline 5 & Área lateral do dossel (equação 1) & $\mathrm{m}^{2}$ & $-0,5786$ & 0,7896 & 0,9760 & $* *$ \\
\hline 6 & Área da seção inferior do dossel & $\mathrm{m}^{2}$ & $-0,5895$ & 1,2795 & 0,9141 & $* *$ \\
\hline 7 & Diâmetro da seção inferior do dossel & $\mathrm{m}$ & $-2,2085$ & 2,6581 & 0,8671 & $* *$ \\
\hline 8 & Área da seção média do dossel & $\mathrm{m}^{2}$ & $+0,0380$ & 2,5378 & 0,7421 & $* *$ \\
\hline 9 & Diâmetro da seção média do dossel & $\mathrm{m}$ & $-0,9224$ & 2,9942 & 0,7216 & $* *$ \\
\hline 10 & Altura do primeiro par de ramos & $\mathrm{m}$ & $-1,2332$ & 8,2287 & 0,0741 & ns \\
\hline 11 & Diâmetro da seção superior do dossel & $\mathrm{m}$ & $+0,8761$ & 5,9690 & 0,0720 & ns \\
\hline 12 & Área da seção superior do dossel & $\mathrm{m}^{2}$ & $+1,1700$ & 32,1130 & 0,0600 & ns \\
\hline
\end{tabular}

ns Não-significativo. $* *$ Significativo a $1 \%$ de probabilidade pelo teste $\mathrm{F}$. 
por planta (modelo 2) apresentaram elevado coeficiente de correlação e foram altamente significativos para serem adotados na estimativa do IAF da planta de café (Tabela 2). No entanto, tem-se como limitação para a adoção destas variáveis a dificuldade, e também a possibilidade de erro, na contagem das folhas no segundo caso; e, pelo fato de se tratar de método destrutivo, no primeiro caso, que considera a massa de matéria seca das folhas.

As variáveis associadas à arquitetura de copa da planta, com unidades em volume $\left(\mathrm{m}^{3}\right)$ e em área $\left(\mathrm{m}^{2}\right)$ do dossel do cafeeiro (modelos 4 e 5 , respectivamente), apresentaram elevado coeficiente de correlação e foram altamente significativas para a estimativa do IAF da planta de café. Assim, tanto o volume (Vc) quanto a área lateral do dossel (Ac), da figura geométrica representativa da parte aérea do cafeeiro, admitida cônica, ajustaram-se adequadamente ao IAF estimado.

De acordo com o procedimento metodológico descrito, substituindo-se os modelos 4 (X = Vc: volume do dossel do cafeeiro, equação 2, Tabela 2) e 5 (X = Ac: área lateral do dossel do cafeeiro, equação 1 , Tabela 2), que apresentaram maiores coeficientes de correlação, na equação 3 , pode-se estimar o IAF da planta de café por meio das equações 4 e 5 , respectivamente:

$\mathrm{IAF}=0,0134+2,7791 \mathrm{Vc}=0,0134+0,7276 \mathrm{Di}^{2} \mathrm{Hd}$ $\mathrm{IAF}=-0,5786+0,7896 \mathrm{Ac}=-0,5786+0,6201 \mathrm{Di}\left(\mathrm{Di}^{2}+\right.$ $\left.4 \mathrm{Hd}^{2}\right)^{0,5}$.

Ressalte-se que o referido método não é destrutivo, e as variáveis que serão utilizadas como a altura do dossel (Hd) e diâmetro da seção inferior do dossel (Di) da planta são facilmente mensuráveis (Figura 1).

\section{Conclusão}

O volume e a área lateral do dossel do cafeeiro (Coffea arabica L.) e, conseqüentemente, a altura e o diâmetro da seção inferior do dossel (copa do café) podem ser utilizados para a estimativa do índice de área foliar do cafeeiro.

\section{Referências}

ASSMANN, E. The principles of forest yield study. Oxford: Pergamon, 1970.506 p.

HUERTA, S. A.; ALVIM, P. de T. Índice de área foliar y su influencia en la capacidad fotosintética del cafeto. Cenicafe, Caldas, v. 13, n. 2, p. 75-84, 1962.

LEONG, W. Canopy modification and its effects on the growth and yield of Hevea brasiliensis Muell. Arg. 1980. 283 p. Thesis (Ph.D.) - Faculty of Agriculture Sciences of Ghent, Ghent.

PEREIRA, A. R.; VILLA NOVA, N. A.; SEDIYAMA, G. C. Evapotranspiração. Piracicaba: Fealq, 1997. 183 p.

REY, R.; ALVAREZ, P. Evaluación de diferentes ecuaciones de regresión en la estimación del área foliar del cafeto en vivero a partir de sus medidas lineares. Agrotecnia de Cuba, Habana, v. 23, n. 3/4, p. 69-74, 1991.

SANTINATO, R.; FERNANDES, A. L. T.; FERNANDES, D. R. Irrigação na cultura do café. Campinas: Árvore Agrícola, 1997. 146 p.

VALENCIA, G. A. Relación entre el índice de area foliar y la productividad del cafeto. Cenicafe, Caldas, v. 24, n. 4 , p. 79-89, 1973.

WATSON, D. J. The physiological basis of variation in yield. Advances in Agronomy, San Diego, v. 4, p. 101144, 1952. 